\title{
Songs of the Stones: An Investigation into the Acoustic Culture of Stonehenge
}

\author{
Dr. Rupert Till \\ University of Huddersfield, UK. \\ r.till@hud.ac.uk
}

\begin{abstract}
This paper is an investigation into the acoustic culture of Stonehenge. It begins by discussing the importance of music and sound in the life of an aural/oral culture, and its importance as ritual technology. It goes on to provide background about the site in prehistory and in popular culture. Thomas Hardy's writing about Stonehenge raises the question of whether there are significant acoustic features at the site. There is then a study of the acoustics of Stonehenge, beginning with existing work on the subject and a theoretical consideration. It goes on to study the acoustics of a full size replica and a digital model before discussing the results of field tests in the stone circle itself. It concludes that the sonic features of Stonehenge were noticeable and significant, and that it is likely that they were a part of the ritual culture of the site.
\end{abstract}

Keywords: Stonehenge; Prehistory; Acoustics; Music; Sound; RItual; Solstice; Popular Music.

\section{Introduction}

This work will focus on Stonehenge, a well-known British megalithic prehistoric monument and a significant pre-historical ritual site. There are many theories about the reasons for the construction of the monument, but much about the site is still unknown. This project aims to investigate its acoustic and surrounding musical culture, as although the visual and physical dimensions of the site have been widely explored, its sound remains little studied. There is evidence that Stonehenge has interesting sonic properties, and it is hoped that a further understanding of these properties, can inform the broader understanding of this iconic stone circle.

According to Nettl, most ritual involves music. He underlines,

the importance of music in ritual, and, as it were, in addressing the supernatural. This seems to me to be truly a universal, shared by all known societies, however different the sound. Another universal is the use of music to provide some kind of fundamental change in an individual's consciousness, or in the ambiance of a gathering (...) and it is virtually universally associated with dance; not all music is danced, but there is hardly any dance that is not in some sense accompanied by music. (2000, p. 469).

Although the claim for universality of culture is to some extent problematic, this offers a starting point for further inquiry. 
Music has a vital role in human culture, is a key human technology for building and maintaining community. Freeman (2000, pp. 420-21) tells us that a "significant discovery by our remote ancestors may have been the use of music and dance for bonding in groups larger than nuclear families", and that music "may have accompanied or even preceded the invention of fire, tools and shelter, because the maintenance, development, and transmission across generations of information about techniques for working matter into useful forms must have required existence of channels to support social interactions".

Ehrenreich (2006, p. 14) uses Durkheim's term "collective effervescence" to describe ecstatic merger with the group, and Turner's term "communitas" or "the spontaneous love and solidarity that can arise within a community of equals" (2006, p. 10) to describe the result.

In an aural and oral culture, music and sound would have been a vital element of human life, and without being surrounded by the sounds of musical activity, and the acoustic of modern buildings, the sounds that were heard in prehistory would have had different significance. Ritual in many human cultures involves music, and it often provides the primary structure for activities that construct meaning.

Experiences of self-loss and trance are important for inserting the individual into the group and sustaining community, and music and dance are significant elements of such ritual activity. Although we now conceptualise music and dance as separate, they are very closely related, for example clapping can be described as either, or both. Although there are dangers in assuming that traditional cultures today are the same as prehistoric cultures of the past, archaeologists have often investigated such traditional cultures in order to understand how oral/aural culture operates, and this raises some interesting issues, and helps to remind those of us steeped in modern western culture that our ancestors may have had very different experiences.

For example Ehrenreich has described how music, dance, ritual and religion are often intertwined in some parts of the world, or even defined by a single term.

In large parts of Africa, for example, the identification between communal dance and music, on the one hand, and what Europeans might call "religion" on the other, was profound. The term the Tswanas of Southern Africa use for dance (go bina) also means "to venerate," and in the Bantu language group of southern, central and eastern Africa, the word ngoma can mean "ritual," "cult", "songdance" or simply "drum" (2006, p. 157).

It is important to remember that in prehistory, as McLuhan (1962, p. 28) puts it, "among peoples at an 'oral-aural' level of culture to whom writing was unknown, the ear exercised an overwhelming tyranny over the eye." Music is an important part of popular cultures today, but its impact may have been even stronger in prehistory, perhaps much as Gray describes music in traditional African cultures.

In the African world music has played such a central role in the life of its people for so long that there is often no separate word for it in indigenous languages. Like religion, music permeates the societies of sub-Saharan Africa in a way difficult to understand in the west. An essential vehicle for communicating with God and the ancestors, a key determinant in rites of passage from birth to death, a tool for healing the ill, educating the young, settling disputes and entertaining the communities of both rural and urban Africa, music is perhaps the essential foodstuff for the African mind, body and spirit. To paraphrase Kango scholar Dr. K.Kia Bunseki Fu-Kiau: "To understand music is to understand life itself" (1991, p. 15). 
The study of the sonic culture of Stonehenge allows us to animate the often static image of this iconic site produced by traditional archaeological techniques, as music and sound are time based media. As Ingold tells us,

\begin{abstract}
when it comes to affairs of the soul, of emotion and feeling, or of the "inwardness" of life, hearing surpasses seeing as understanding goes beyond knowledge, and as faith transcends reason (...) Vision in this conception, defines the self individually in opposition to others; hearing defines the self socially in relation to others $(2000$, p. 246$)$.
\end{abstract}

Like Ingold, Gibson emphasises the importance of an ecological and holistic approach to perception, stating that sound gives "information about the temporal structure of the event that caused it and the vibratory frequency of this event . . . with great precision" (1996, p. 17).

This paper will begin by outlining Stonehenge's archaeological context, and its reception in contemporary popular culture. It will look briefly at suggestions of acoustic effects at Stonehenge in the work of author Thomas Hardy. It will go on to present an acoustic analysis of the site, from a theoretical perspective as well as using field tests, full scale and digital models, before drawing conclusions about the nature of the acoustic culture of Stonehenge.

\title{
Context
}

The first stage of building at Stonehenge started approximately 5000 years ago, and new developments continued for about 1500 years. Stonehenge is perhaps Britain's best-known stone circle. Although it is not the largest or most impressive, and although it is not strictly speaking actually a henge monument, it is unique due to the quality of the dressing of the stone, and the structure of the stone settings, including horizontal stone lintels held in place by woodworking-like joints. Extremely hard sarsen stone was used for the outer circle of uprights and lintels, as well as huge arches made of three stones called trilithons. Other stones, which were mostly finally placed within the sarsen circle, are called bluestones, many of which were probably brought from Wales, the first stones at the site, preceded by earthworks and timber structures. The stones were rearranged a number of times, and the exact details of this process are uncertain. The analysis in this paper deals with the final phase of development, known as Stonehenge 3vi.

Stone circles are numerous in Britain, but remain mysterious, and archaeologists are still not certain about the purpose of these structures. However, it is generally accepted that Stonehenge would have been a ritual site, and is aligned to the sunrise and sunset on the summer and winter solstices. There are many archaeological books discussing Stonehenge, including Cleal et al. (1995) and Richards (2007). There are two competing current principal theories about what Stonehenge was used for in prehistory. Mike Parker Pearson and the Stonehenge Riverside Project suggest that the site was a place for or city of the dead or ancestors (Parker Pearson et al., 2006), while Tim Darville suggests that it was a site of healing (Wilson, 2009).

\section{Stonehenge in contemporary popular music culture}

There may be some similarity between the ritual activities that occurred at Stonehenge in prehistory and those within contemporary culture. Consider, for example, press reports related to this research. The conservative UK broadsheet newspaper The Daily Telegraph reported on its website that "Stonehenge was giant 
concert venue", (Daily Telegraph, 2009). It is perhaps not surprising that this newspaper, whose target audience consists of higher socio-economic groups, suggest that this is a venue for music to be performed by professional musicians to an audience, as an art form. However there is little evidence that this is the case. The sense of envelopment and lack of a stage indicate that musical activity here was more likely to be participatory. British tabloid paper The Sun is perhaps closer when it says "Henge a venue for partying", (Whelan, 2009). The website of MSNBC, with a similarly broad target audience, describes "Stonehenge: one totally awesome rave location", (Lorenzi, 2009). These publications suggest a participative event full of selfloss, ecstatic experiences and rhythmic dancing. There is perhaps some truth in all of these headlines, even though they are somewhat simplistic and only engage with the research on a very superficial level.

Stonehenge shows evidence of those who were most involved being within the centre of the stone circle, with others of lower status staying further outside the sarsen ring, but within the surrounding bank and ditch; and also shows evidence of likely rhythmic musical activity. All three of the above media sites seem at first glance to play down the ritual and religious meaning of the activity at Stonehenge. However concert halls are places of ritualised performance, identity formation, community, celebration and social stratification, much like Stonehenge, with those able to access the most exclusive seats closest to the centre of activity, having higher social status and power than those on the peripheries. As will be shown later, the acoustics of Stonehenge imply the possibility that in prehistory a large number of people would have gathered to take part in a participative ritual featuring amplified simple, rhythmic repetitive music and the achievement of trance like states. Similar activities are present at 'rave' events within Electronic Dance Music Culture (EDMC), which has been described by many commentators as having ritualistic or religious meaning for its participants (Till, 2009a; St. John, 2004).

In the last 50 years Stonehenge has become increasingly associated with music and musical culture. It has been referenced in numerous song titles and lyrics as well as on album covers. It featured in the Beatles film Help! (1965), and from 1972 until 1984 it was the site of the Stonehenge Free Festival, a music festival that occurred annually to mark the summer solstice. It was perhaps the least regulated of British music festivals of the 1970s. Attendance at the event became a badge of subcultural capital, authenticity and credibility for rock music fans, the antithesis of commercial music culture, and performing at the festival had a similar effect for bands.

Many bands have associated themselves with Stonehenge. For example Ten Years After released their Stonedhenge album in 1969 before their Woodstock festival appearance. Richie Havens, another Woodstock performer, called his 1970 album Stonehenge, and both these albums featured the stones on their covers. Hawkwind in particular became known for performing at the Stonehenge festival each year. Their 1976 tour was entitled Atomhenge, as the stage set was based on Stonehenge, and their associated 1976 album Astounding Sounds, Amazing Music, was on the Atomhenge label. Their 1983 album Zones featured Stonehenge on the front cover, and a DVD entitled Hawkwind - The Solstice at Stonehenge (2004) records a performance at the festival. In 1985 fear of damage to the site by the 65,000 who had attended the year before, led authorities to ban the festival, leading to the violent Battle of the Beanfield between new age travelers and the police (Worthington, 2005).

Aerosmith's album Rock in a Hard Place (1982) also featured images of Stonehenge on the cover, but it was perhaps Black Sabbath's Born Again album which unwittingly finally sealed Stonehenge's place in rock music history. Featuring ex-Deep Purple singer lan Gillan, the album featured a short instrumental piece call 
called 'Stonehenge'. Band manager Don Arden (father of Ozzy Osbourne's wife Sharon), had a stage set featuring Stonehenge built for the subsequent tour, but sent plans to the makers that were wrongly specified in metres instead of feet (Mclver, 2006 , p. 166). The resultant set was so large it could not fit in most venues although it was used at the Reading Rock festival in 1983. A year later, spoof rock band Spinal Tap parodied this mistake in the film This is Spinal Tap (1984), playing with the iconic nature within rock circles of Stonehenge, ironically enough in the year that the Stonehenge Free Festival last occurred. In the film the band played a song called 'Stonehenge' and had a stage set designed featuring the stones, although in this case the set was accidentally built too small instead of too large. The popularity of This is Spinal Tap amongst rock music fans, has reinforced the link within popular culture between Stonehenge and rock music. In addition, in the video game Guitar Hero on the Sony Playstation 2 console, the finale of the game is set at Stonehenge, accompanied by dancing druids with a hovering UFO providing a light show. In recent years English Heritage (who manage the site) have organised public access to the site for the celebration of the summer solstice, and approximately 20,000 people attend each year. At these events no amplification is allowed, but drums and other acoustic instruments are common.

\section{Thomas Hardy and Stonehenge}

There have been a number of links between musical culture and Stonehenge. Tess of the D'Urbervilles novelist Thomas Hardy has suggested that Stonehenge produces interesting sounds.
All around was open loneliness and black solitude, over which a stiff breeze blew (...)
'What monstrous place is this?' said Angel.
'It hums,' said she. 'Harken!'
He listened. The wind, playing upon the edifice, produced a booming tune, like the note of some gigantic one-stringed harp. No other sound came from it ... At an indefinite height overhead something made the black sky blacker, which had the semblance of a vast architrave uniting the pillars horizontally. They entered carefully beneath and between; the surfaces echoed their soft rustle; but they seemed to be still out of doors ...

'What can it be? (...) A very Temple of the Winds' (...) 'It seems as though there were no folk in the world but we two' (...) they (...) listened a long time to the wind among the pillars (...) Presently the wind died out, and the quivering little pools in the cup-like hollows of the stones lay still (1891, pp. 510-3).

Here, Hardy describes Stonehenge through its sonic qualities, emphasising this by setting the scene at night so that the characters cannot see the site. $\mathrm{He}$ describes that strong winds make the site resonate with a loud, low frequency hum, or booming tune. This seems likely to be a standing wave, a resonance, as if Stonehenge were a large bottle, and the wind were a person blowing over the top of it to make a sound. Further evidence of the presence of standing waves comes from the quivering of water in pools in hollows in the stones, which could be caused by sound vibrations.

Hardy also describes echoes in the space, the sounds made echoing from the surfaces of the stones. This is a description of reverberation, caused by sound reaching a listener via many paths, after hitting walls or other solid surfaces. One might think of Stonehenge as being an outdoor space, and therefore as not having the kind of reverberation comparable to an indoor space such as a church, concert 
hall or bathroom. Indeed Hardy comments that his characters are surprised to hear such effects when they were still outdoors. It seems that the characteristic circular shape of Stonehenge, and the dense stone it is made from, creates noticeable acoustic effects, even though half of the 'building' has collapsed and many of the stones are missing or out of place.

In an interview published in The Daily Chronicle on 24 August, 1899, Hardy also discusses sound. Hardy lived near Stonehenge, referred to it in other works, and was worried at the time of the interview that the site was about to be sold on the open market, stating that it should be put into public ownership. When asked about the notable features of the site, he states that, "If a gale of wind is blowing the strange musical hum emitted by Stonehenge can never be forgotten". This may have been common knowledge amongst Victorians, as Hardy adds, "I have no more knowledge of the monument than is common to, or obtainable by, anybody who chooses to visit it" (Orel, 1966: 196-200). He suggests that dramatic low frequency resonance effects are audible at Stonehenge, which were regarded as one of the site's most impressive features. Hardy's writing raises an important question, which is used as a starting point for the following acoustic research: is it possible that specific acoustic effects are a significant feature at Stonehenge?

\section{The acoustics of Stonehenge 3vi}

Watson and Keating (1999) carried out an initial pilot study into the acoustics of Stonehenge. They discovered modal resonance in the space, filtering of low frequencies, and that the stones are curved and polished, purposefully shaped. The inside of the stones are concave, whereas the outsides are not shaped in this way, implying that they may have been intentionally shaped, potentially for acoustic purposes. Working with acoustics specialist Dr. Bruno Fazenda, I began a project to investigate further the acoustics of the space. This project included theoretical acoustic analysis of plans of the monument; acoustics tests at a full size replica of Stonehenge in the USA; analysis of a digital model of the site; and acoustic tests at Stonehenge itself.

Theoretical analysis of plans of Stonehenge immediately suggested that there would be a number of acoustics effects present at the site. Mapping ray paths of how sound would reflect off different surfaces indicated that there would be reverberation at the site when it was in its original form. Although this is unusual in outdoor sites, the circular arrangement and reflective quality of the stones could produce reverberation in this case. Although a number of prehistoric sites had been described as having acoustic features (Devereux, 2001), to suggest that stone circles could have reverberant fields, as opposed to standing waves and echoes, was a new proposal.

The most intriguing design feature of Stonehenge from an acoustic perspective was the ring of stone lintels. It is not surprising that any stone circular building would have strong acoustic effects, as circular modes of vibration, with a number of harmonics, are supported by the geometry of the building. There are a number of well-known religious buildings that have circular features, and many of them have interesting and well-known acoustic properties. St. Paul's Cathedral in London has a circular dome that is known for having a whispering gallery effect. A whispering gallery allows one to speak next to the wall in a whisper and be heard a great distance away around the curve of the wall, too far to be heard under normal circumstances. In Pisa, in the Piazza Dei Miracoli, the cathedral has not only a famous leaning bell tower, but also a remarkable leaning baptistry, a large circular building. Staff regularly demonstrate the astonishing acoustics in the space to tourists by singing individual single notes that are sustained so powerfully that they sound 
like a chord. In Beiljing, the Imperial Vault of Heaven in the Tian Tan temple complex has at its centre a circular building, which is surrounded by a large circular 'echo wall' that has a whispering gallery effect. It also features echo stones; at the first one hears one echo, at the second two echoes and at the third three echoes. The ritual activities at the site are linked to the summer solstice, and to the joining of heaven and earth. That many circular ritual spaces are associated with acoustic effects and sound, suggests that perhaps it would be reasonable to expect the same to be true at Stonehenge.

Let us consider the most obvious paths of sound in a circular stone building. If standing in the middle of an open field, when one makes a sound it leaves you and keeps traveling away, thus there is no reverberation. If one stands in a rectangular building and makes a sound, it leaves you, hits various walls at different times, and reflects back to you at different times, creating reverberation as the echoes created merge together. If standing at the centre of a circular building, when one makes a sound it leaves you, hits and reflects straight back from the wall at all points of the circumference simultaneously, and these reflections return to you at the same time. In a large enough space this would produce a prominent echo and reverberation from the combination of a number of 'echoes', or reflections.

If standing at the edge of a circular space, when one makes a sound it will leave you, reflect back off the wall directly opposite and return as a slightly later echo; travel to one side reflect off the wall twice making a triangular shape and return a little later still; hit a wall three times making a square shape and return a little later; hit five walls forming a pentangle and return a little later; and so on. The overall effect would be echoes (in a large space) or resonance/reverberation (in a smaller space where the differences in distance are small and so the sounds are not distinguishable). In circular stone spaces the size of Stonehenge it appeared likely that there would actually be both reverberation and echoes.

It seemed that Stonehenge could be made to resonate further by producing sound in time with the echoes in the space. One could make Stonehenge resonate, much like blowing over the top of a bottle to make it hoot, or like running one's finger around the top of a glass; or hitting the skin of a drum. This would work by making the air in the space vibrate at its fundamental resonant frequency. Measurements of the diameter of Stonehenge told us that this frequency would be about $10 \mathrm{~Hz}$. Stonehenge is of course not a simple circle, it is a complex monument involving a number of geometric shapes. However despite this, theoretically it should still have a strong fundamental resonance at this frequency. The circle of stone lintels placed on the outer ring of upright sarsen stones protudes largely above any other stones, and would provide an almost unheeded clear ring of stone, and any resonant effects could be supported by the upright stones that support the ring of lintels.

That the fundamental resonant frequency of Stonehenge was $10 \mathrm{~Hz}$ raised a number of interesting questions. Different types of brain waves that are present during various different mental states have specific typical dominant frequency ranges. $10 \mathrm{~Hz}$ is a frequency that when detected in the brain is described as an alpha wave pattern. As alpha waves are often associated with relaxation, altered states of consciousness, meditation, and new age religious practice, that Stonehenge may have produced these frequencies raises a number of issues.

A $10 \mathrm{~Hz}$ frequency is often inaccurately described as being below the point which humans can hear, sometimes described as infrasound. This is something of a myth. Although sine waves cannot usually be heard if their pitch is below $20 \mathrm{~Hz}$, in fact, as humans age it is possible to hear lower notes than this, and this ability varies from person to person. It is also possible to hear notes lower than $20 \mathrm{~Hz}$, they simply have to be increasingly loud in order to hear them. In addition, periodic rhythmic vibrations with frequencies below $20 \mathrm{~Hz}$, such as a series of short impulses or clicks, 
can also be heard below this point. In fact it might be clearer to suggest that periodic repeating sound is perceived differently at different frequencies.

At a frequency of $20 \mathrm{~Hz}$ and above, repeating sounds are heard as pitched 'musical' notes. When air moves more than 20 times a second, one cannot distinguish the oscillations individually, and one perceives a sustained pitched note, in the same way that when one sees a film moving at twenty or more frames per second, one cannot see the individual images and instead perceives a single moving image. Between 14 and $20 \mathrm{~Hz}$ one often feels sound as much as one hears it, often as a vibration or rattle.

From 1 to $14 \mathrm{~Hz}$ one perceives frequencies as rhythms, whether a drum pattern or the rhythmic sound of a train. These frequencies are usually described as a number of crotchet beats per minute, or bpm. For example $2 \mathrm{~Hz}$ equates to two beats per second, or 120 beats per minute, $3 \mathrm{~Hz}$ is three oscillations per second, or $180 \mathrm{bpm}$. Above $3 \mathrm{~Hz}$ one typically subdivides the rhythm, perceiving $4 \mathrm{~Hz}$ as the same tempo as $2 \mathrm{~Hz}$; as the same speed, but with a doubled pulse, as $120 \mathrm{bpm}$ with a quaver (eighth note) pulse. This is partly because music may well have sections where there are only quavers or only crotchets (quarter notes), the music feels faster when there are quavers but the tempo is the same as when there are crotchets. Below $1 \mathrm{~Hz}$ one perceives frequencies as time. $1 \mathrm{~Hz}$ is one oscillation a second, which is also $60 \mathrm{bpm}$. How one perceives sustained oscillations of sound is summarized in Table 1 below. A ticking clock has a frequency of $1 \mathrm{~Hz}$, but one would often describe this as a time period rather than a frequency, as a second. One would more usually describe $0.5 \mathrm{~Hz}$ as two seconds, and $0.0167 \mathrm{~Hz}$ as a minute.

Table 1 - Perception of sound at different frequencies.

\begin{tabular}{|c|l|}
\hline Frequency & Perception \\
\hline Above $20 \mathrm{~Hz}$ & Pitch or musical note \\
\hline $14-20 \mathrm{~Hz}$ & Vibration \\
\hline $1-12 \mathrm{~Hz}$ & Rhythm \\
$1-3 \mathrm{~Hz}$ & $60-180 \mathrm{bpm}$, crotchet pulse \\
$2-6 \mathrm{~Hz}$ & $60-180 \mathrm{bpm}$, quaver pulse \\
$4-12 \mathrm{~Hz}$ & $60-180 \mathrm{bpm}$, semi-quaver pulse \\
\hline $0-1 \mathrm{~Hz}$ & Time \\
$1 \mathrm{~Hz}$ & 1 second \\
$0.5 \mathrm{~Hz}$ & 2 seconds \\
$0.0167 \mathrm{~Hz}$ & 60 seconds or 1 minute \\
\hline
\end{tabular}

There is some overlap at the boundaries of our perception. Our system of measurement of frequency makes it awkward to describe minutes, hours, days or years as frequencies, and yet they are all periodic variations, they are all essentially measurements of time. Our perception of time is controlled partly by our physicality, the ability of the ear to distinguish between oscillations; partly by our minds, by the how the brain processes and perceives different frequencies and periods; and partly by the interpretation and cultural understanding of these functions, depending on 
tradition and language. Different periodic oscillations are delineated linguistically, and mathematical systems are set up to work within human traditions and perceptions. Terms like frequency $(\mathrm{Hz})$ and period (seconds) are useful in different situations, and are perceived differently, even though they are essentially the same thing.

$10 \mathrm{~Hz}$ can be described as $150 \mathrm{bpm}$ with a semi-quaver pulse, or as a time period of $0.1 \mathrm{~s}$. Although our research model predicted that these low frequencies would be created by reflections inside the stone circle, research also showed that the stones outside the main sarsen stone ring, called the Slaughter and Heel stones, were positioned so that they interact with the acoustics at the centre of the space, reinforcing these sonic effects.

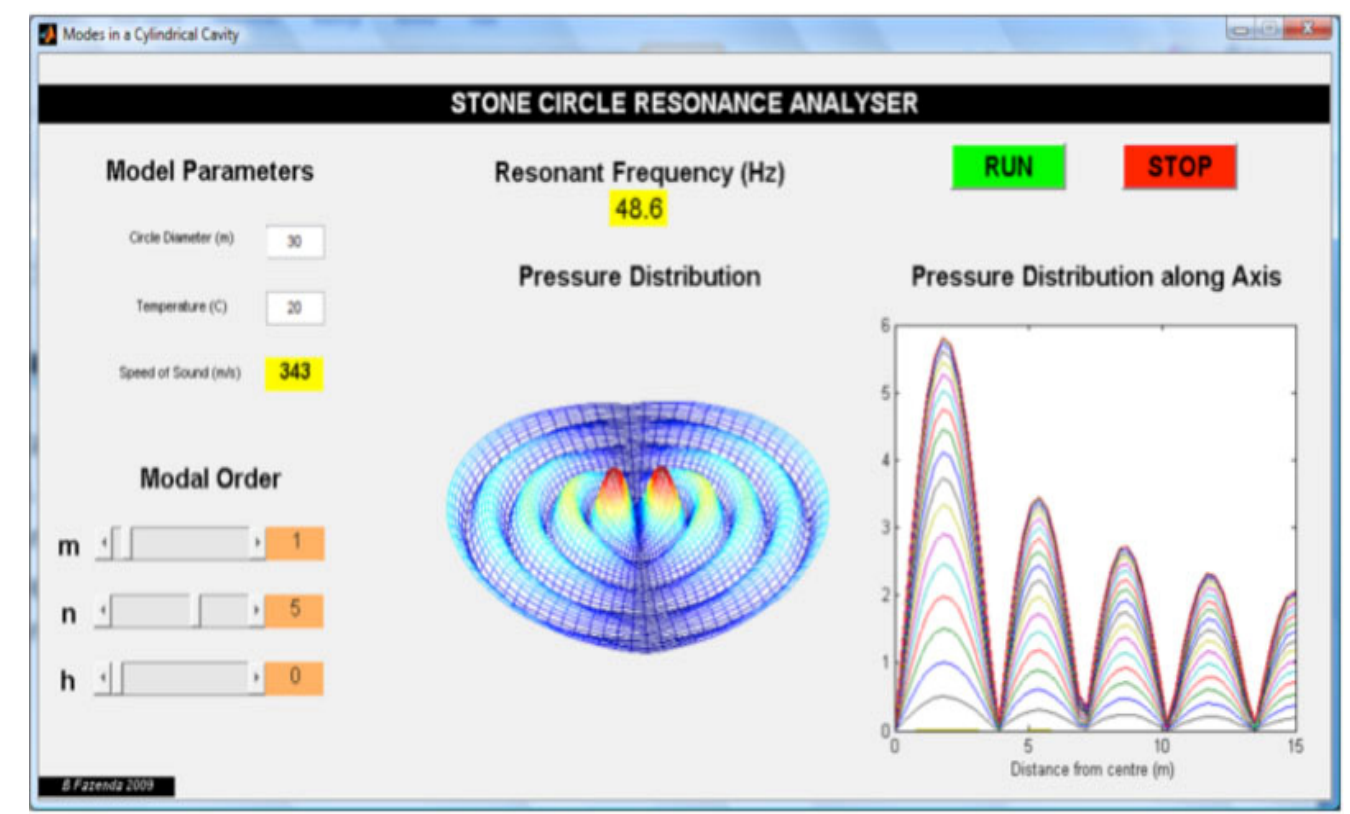

Figure 1 - Mathematical model for predicting resonances in a stone circle

It was theorised that these low frequency resonances and echoes in the space would take the form of circular modes, similar to those on drum skins, or more accurately in cylinders, rather than the straight standing waves often described in strings or pipes. My colleague Dr. Fazenda produced a mathematical model (figure 1) to calculate the resonant frequencies of a circular space, allowing one to vary the circle's diameter and ambient temperature, as well as to calculate and illustrate resonant frequencies of various modes of vibration present. This model predicted that there would be two strong modal resonances at about $48 \mathrm{~Hz}$ in the space, meaning that this frequency is particularly reinforced.

\section{Using the Maryhill Monument as a scale model of Stonehenge}

This theoretical model needed to be tested, but there were a number of difficulties. The main issue was that the prehistoric Stonehenge that had been analysed is not an intact structure, as many as half of the stones are missing or fallen. Acoustic tests at Stonehenge itself would therefore not confirm our theories regarding its original acoustics. What was required therefore was a scale model that could be tested. Fortunately such a thing already existed. In Maryhill, in Washington State in the USA, is a war memorial built in the shape of Stonehenge. It was decided to use this as a full size scale model, and to carry out acoustic tests there. 
However, the Maryhill Monument was made from concrete rather than stone. It was also set in a very different environment to the original. It is based on archaeological plans accurate in 1918 when building was begun. The stones are all a regular size and shape, although their faces have been made artificially rough by placing metal objects in the concrete, to make the site appear older. The central altar stone was set lying down rather than upright, and the Heel Stone was not correctly placed. The lintels are also attached to, rather than placed on, the uprights. All of this meant that acoustic results would not be exactly accurate. However, the basic size and shape of the monument was comparable, and the results of acoustic tests therefore provided an indication of the acoustic effects that might be present at Stonehenge itself.

Concrete is not the same as stone, it is more porous, especially in this case, since the sand used had been polluted by a seawater flood in the area, making the concrete even more porous than it would usually be. This means that reflections, and therefore acoustic effects, are less strong than those produced by the polished, curved, and specially chosen stones at Stonehenge, and that as a model Maryhill produced conservative rather than exaggerated results and acoustic effects.

According to Devereux (2009) at least some of the stones at Stonehenge may have been sourced for their acoustic properties, as the Bluestones from Wales came from an area called 'ringing rocks'. He has tested similar stones that remain in Wales, has found that a high proportion of them resonate when struck, and has conducted research into rock gongs and other lithophones found in various ritual cultures. It took an enormous effort in prehistory to transport the bluestones from Wales, and there is evidence that at least part of the reason for these particular stones to be selected and moved was due to their acoustic properties.

Testing the Maryhill Monument using calibrated sine sweep signals, showed that T30 (reverberation time) was $1.5 \mathrm{~s}$, and that EDT (early decay time) was $0.8 \mathrm{~s}$. There was certainly reverberation noticeably, if subtly, present. Echoes were clearly audible in the centre of the circle reflecting from the Heel stone. As predicted by the theoretical model, the very centre of the space was a focus of acoustic effects.

Modal resonance was stimulated in the space using single low frequency tones, generated by specialist dodecahedron and sub-bass loudspeakers, and this confirmed that there the strongest resonance was at about $48 \mathrm{~Hz}$, again matching the results from the theoretical model. Patterns of maximum and minimum loudness were mapped out, caused by this resonance, and these matched the predicted modal patterns. These are shown in figure 2, with the levels mapped in red and shown on a plan of Maryhill. The peaks of the resonance are extrapolated into blue circular maps of loudness maxima which correspond to the placement of stones, and theoretical modes are shown in green and yellow. In some positions very little of this bass frequency sound was heard, whereas at other positions it was amplified. For example at the opposite edge of the stone circle the sound was as loud as when standing next to the loudspeaker.

It also proved possible to stimulate the same resonances by using rhythms rather than sine waves. This was achieved firstly with a simple bass drum sound, then with more authentic sounds. Audio example 1 is a recording made while moving around Maryhill. One hears the sound change due to the modal resonance in the space. The original dry sound is a simple bass drum. The resonance of the space makes this sound at times like a bass synthesizer.

To establish whether a group of instruments available in prehistory could produce the same effect, a computer was used to play sampled sounds at the same tempo. These samples were recordings of replica clay TRB prehistoric drums created by Simon Wyatt, based on his research (Wyatt, 2008). This method also produced powerful standing waves. The tempo used was the equivalent of the frequency of the 


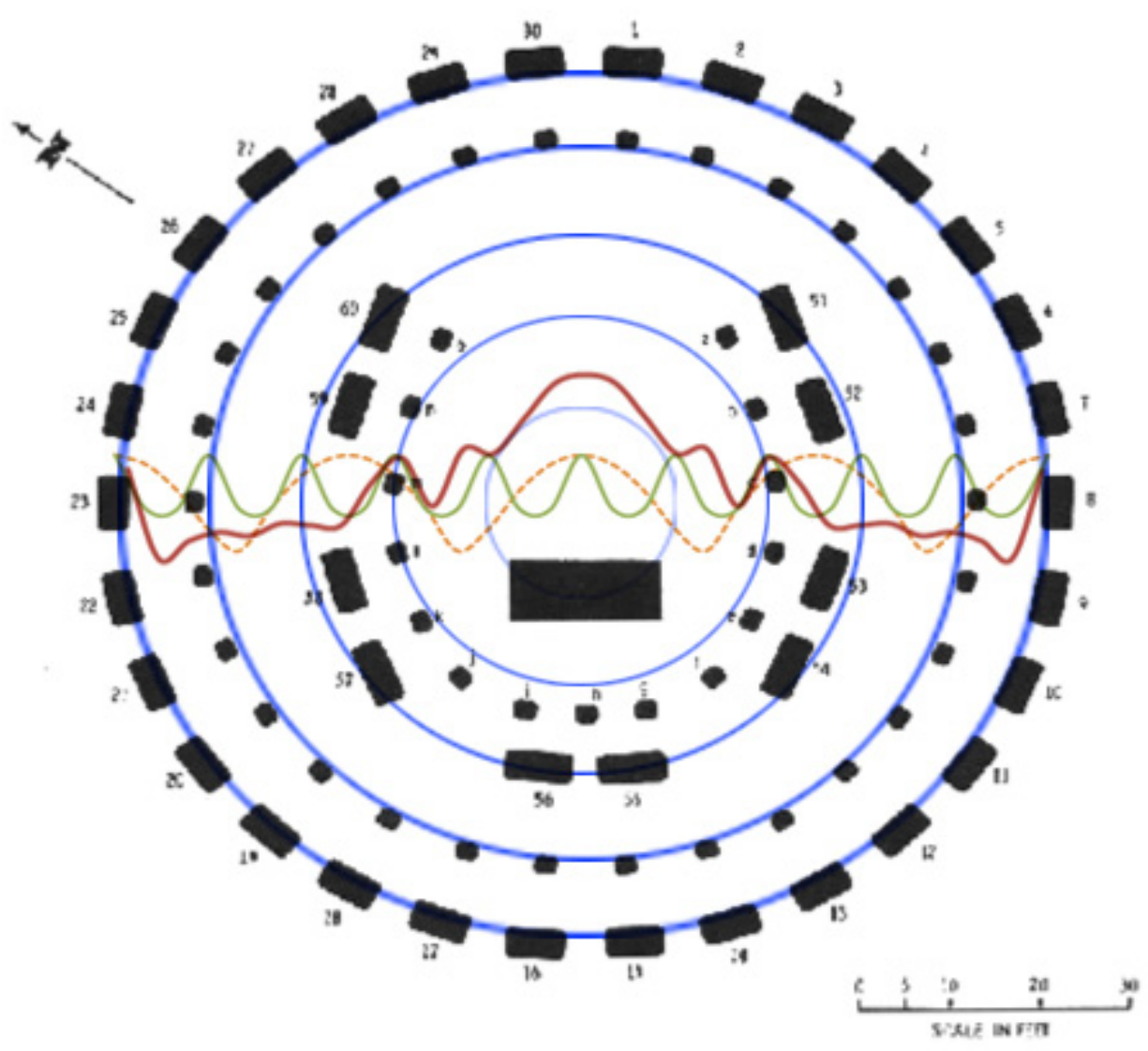

Figure 2 - Mapped levels of a $48 \mathrm{~Hz}$ standing wave at Maryhill

echoes detected in the space, which was about $156 \mathrm{bpm}$. The tempo was varied, until resonance was detected in the space. The percussion sounds produced the peaks and troughs in volume, and softened attack portions of the sounds, that are typical of standing wave or modal resonance. There was also evident a pronounced $48 \mathrm{~Hz}$ sustained bass tone, especially at the edge of the circle.

This latter experiment was significant because the $48 \mathrm{~Hz}$ waveform played through loudspeakers that was used at first to create standing wave resonance, could not have been produced in prehistory. It was important to show that modal resonance could be achieved using the sounds of small hand percussion instruments, using instruments and sounds that could have been available in prehistory.

\section{Acoustic analysis of a digital graphical model, and field tests at Stonehenge}

In order to try to verify results from Maryhill, and further explore the acoustics of Stonehenge, the acoustics of a digital graphical model of the stone circle was studied using specialist Odeon room acoustics software. Odeon is professional software used by architects to assess the acoustics of concert halls. Unlike other 
cheaper similar programmes it allows for the automatic calculation of a range of standard acoustic measurements, and allows one to see these measurements mapped across the modeled space. It also provides auralisation of the model, allowing one to hear the acoustics of the space. This provided results for measurements such as Clarity (C80), Definition (D50), Loudness (SPL), Envelopment (LG80), Speech Transmission Index (STi), Reverberation Time (T30) and Early Decay Time (EDT).

Table 2 - Acoustic results from Odeon model.

\begin{tabular}{|c|c|c|c|}
\hline Perceived Effect & $\begin{array}{c}\text { Acoustic } \\
\text { Parameter }\end{array}$ & Ideal Range & $\begin{array}{c}\text { Stonehenge } \\
\text { Value }\end{array}$ \\
\hline Subjective Level & G/SPL & -2 to $+10 \mathrm{~dB}(>3)$ & $8.8 \mathrm{~dB}$ \\
\hline Reverberance & EDT & 1 to $3 \mathrm{~s}(2.2 \mathrm{~s})$ & $2.36 \mathrm{~s}$ \\
\hline Clarity & C80 & -5 to $+5(-1$ to 3$)$ & -5.2 \\
\hline Definition & D50 & 0.3 to 0.7 & 0.19 \\
\hline Centre Time & Ts & 60 to $260 \mathrm{~ms}$ & $180 \mathrm{~ms}$ \\
\hline Source Width & LF80 & .05 to $0.35(>0.25)$ & 0.277 \\
\hline Envelopment & LG80 & -14 to $+1 \mathrm{~dB}$ & $6 \mathrm{~dB}$ \\
\hline
\end{tabular}

The modelling results supported those from Maryhill. They also showed that Stonehenge had a remarkably high level of envelopment, and that those inside would feel surrounded by, enclosed by, and included within, the sound and acoustic of the space. Results were comparable with those found in concert halls (Skålevik, 2008), and largely within the range of standard ideal figures (see Table 2), which were taken from Akutek (2008).

Clarity and definition in the space were found to be slightly lower than ideal, while level and envelopment were higher. These figures indicate the space was better for music than for speech. It also indicates that the acoustics would support rhythmic music better than sustained musical sounds. The acoustics also act to engage those within the stone circle and exclude those outside. The strong envelopment would be ideal for activities in which a high level of engagement and participation was required, rather than where some people present were able to remain detached from the activities. Values did vary within the space, and those shown are averaged results. Envelopment was found to be much lower immediately outside the circle. Within the space, moving by as little as $0.5 \mathrm{~m}$ could cause significant changes in sound. Low frequency resonances were predicted by Odeon, as were sonic connections between the centre of the circle and the Heel Stone, Slaughter Stone and other stones outside the circle, although the calculation method of the software means that very low frequency results were inaccurate. 


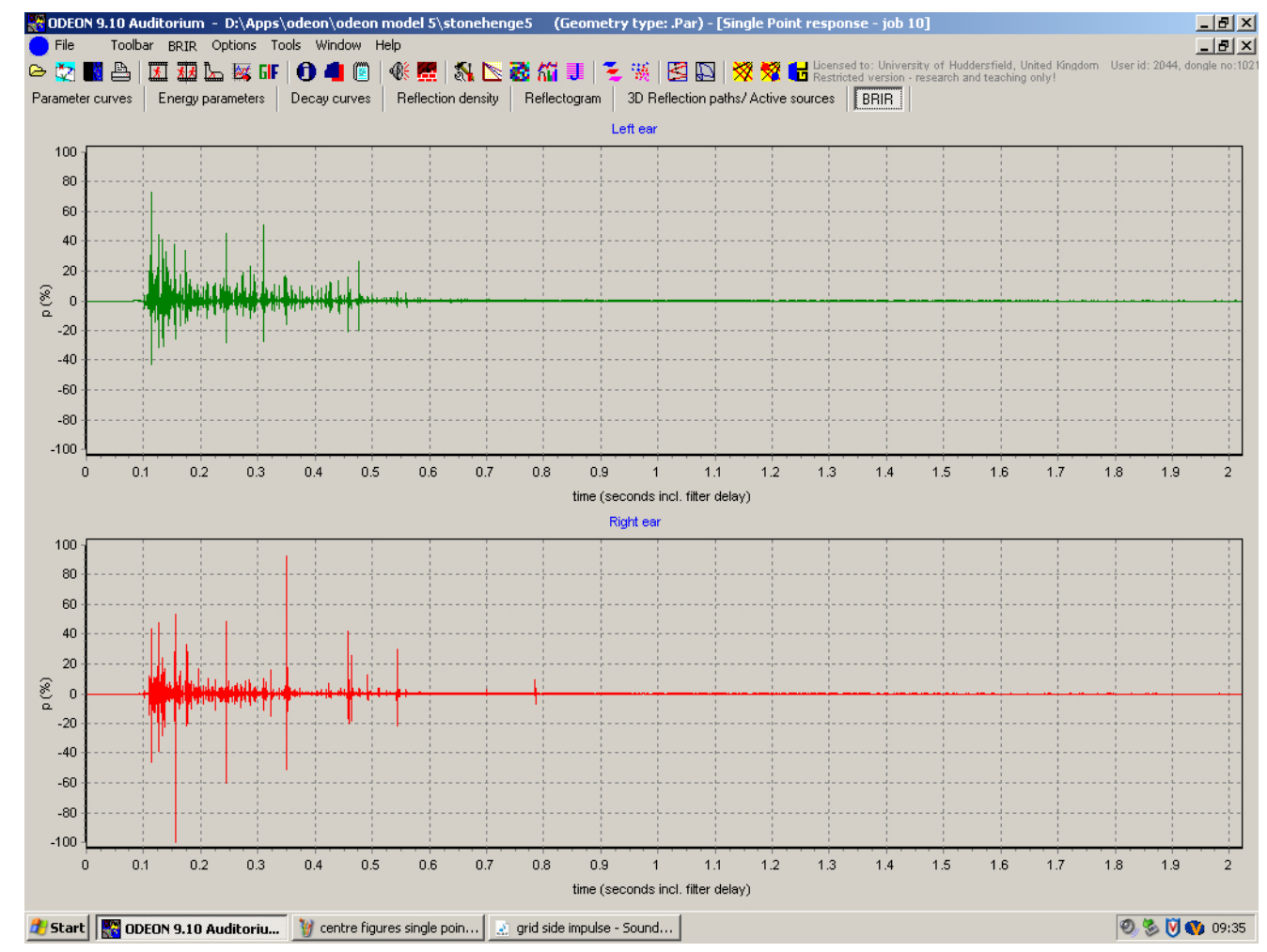

Figure 3 - Binarual Impulse Response (IR) produced by Odeon software.

Digital modelling led to additional insights. Further tests explored the different acoustics of various phases of Stonehenge, the effect of adding extra stones to the structure. Various auralisations and impulse responses of Stonehenge, digital files that were reproductions of the sound within the space (see Figure 3) were created. These made it clear that there were echoes and reverberation in the space, and that these were different depending on the position of sound-maker (source) and listener (receiver). The acoustics of the space were digitally superimposed onto anechoic digital audio files (in other words, sounds without reverberation), making it possible to digitally recreate the sound of Stonehenge as it may have been 5000 years ago. The effect of standing in various different positions was recreated, which made the difference between being inside and outside of the circle very clear, echoes and reverberation for example being far more prominent in the centre.

Audio example 2 is an auralisation (simulation of the acoustics) of Stonehenge 3vi (the final phase of development of the structure), with source at centre (someone clapping at the centre) and receiver (the listener) inside near the entrance at the bluestone inner circle. One can clearly hear echoes in the space, and that if one were in the space it would be difficult to miss them. Audio example 3 is an auralisation of the same positions but within Stonehenge 3ii, an earlier phase of development where there are less stones within the circle, which indicates how the acoustic changed over time. The echoes are less controlled and precise, and it is likely that it would have been apparent to the builders of the site that adding or removing stones changed the acoustic of the space. The increasing complexity and refinement of the space may well reflect not only the increasing complexity of the design of the space, but also the increasing sophistication of the ritual culture associated with the site.

Audio example 4 illustrates Stonehenge 3ii again, but this time with both source and receiver at the centre, standing in different positions. Notice the clear 
single echo returning from various directions simultaneously when standing at the centre. This makes it apparent that the site has a stratification of acoustic interest, with some positions in the space having more importance than others. This may have been a space where the voices of the ancestors were most clearly heard, where the most important ritual participants may have stood. It is possible to extrapolate from a forensic study of the acoustics of an archaeological site, evidence that can provide information about the nature of ritual practice from prehistory that is difficult to explore using other archaeological techniques.

In order to confirm the modelling results, acoustic testing was carried out at Stonehenge itself to look for evidence of the original acoustics, which might still be present in the remaining structure, arriving before dawn on a misty Wiltshire morning. This would have been one of the most important ritual sites in prehistoric Britain, and the research team was reminded of the importance of expectation and history in the perception of ritual experiences, by the impression made on them by the experience of conducting research at Stonehenge.

Basic acoustic testing methods such as bursting balloons and recording the resulting sound were used due to the restrictions imposed by working in a short time frame at a heritage site. When recordings from the balloon bursts were analysed, a reverberant impulse response was measurable. The reverberation time was only half that of what had been predicted, at about $0.75 \mathrm{~s}$, but with half the stones missing that was a comparable result to those from Maryhill and Odeon. A number of other sounds were recorded in the space, including clay replica drums, replica flutes and other instruments, made and played by archaeologist Simon Wyatt, based on prehistoric finds such as the bone flute found near Stonehenge at Wilsford. It was hoped to find echoes and reverberation at Stonehenge; however, as noted earlier, because perhaps half of the original structure were missing or fallen this was far from certain.

Having tried various positions with minimal results, we finally tried playing small hand drums at the edge of the space by the sarsen stones, resulting in clear echoes, doubling the drum pattern played. Particularly, high frequency sounds of small drums, produced the most clear acoustics effects. It was easy and natural to play in time with the echoes in the space, which were clearly apparent. A television film crew was present, making a documentary on the work called Stonehenge, for the History Channel's Mysteryquest series, and the sound engineer was able to pick up and record echoes from the stones quite clearly (History, 2009).

\section{Conclusions}

The combined research evidence supports the acoustic features of Stonehenge suggested by Thomas Hardy's writing and comments. Evidence has been found that low frequency modal resonance and standing waves could indeed have been generated at the site, perhaps by large numbers of participants playing small hand percussion instruments such as clay or wooden drums, or pieces of wood or stones. It also seems likely that these low frequency resonances could be produced by strong winds. This study revealed that there was a hierarchy of position in the space, implying that the different circles around the centre, such as the large bank and various stone circles, demarcated different levels of significance, with the centre the most important position. Being within the sarsen stone ring's circumference would have produced a powerful sense of inclusion and involvement. The stones outside the central circle seem to have had significant acoustic effects associated with them, which would have linked them in perceptually to the main circle. 
There is evidence that $10 \mathrm{~Hz}$ frequencies were present, which may have helped to induce the alpha wave brainwave patterns often associated with relaxation, altered states of consciousness, meditation, and new age religious practice. Some research has linked musical activity to this frequency range (for example Egner and Gruzelier, 2003). Research into entrainment has shown that it is possible that the brain can synchronise, or entrain, to such frequencies, in other words if someone hears, sings or dances to a tempo such as $10 \mathrm{~Hz}$, the brain tends to also exhibit this frequency.

Entrainment can encourage, support, enhance, cause or help a subject in achieving a trance or trance-like state. Musical entrainment and entrancement have been explored by for example Turow (2005) and Di Paolo (1999). This is a developing and somewhat controversial field, but it is possible that if there were $10 \mathrm{~Hz}$ or related frequencies at around $156 \mathrm{bpm}$ in evidence, rhythms generated or supported by the acoustics at Stonehenge, they could have had an effect on those present, changing consciousness or atmosphere, and having an effect on ritual activities, perhaps even helping people to achieve trance states.

The acoustics of the space seemed to suit amplified, participative, rhythmic musical or sound making activity, where a number of people were taking part in a ritual activity. It was possible that this was some kind of trance-like ritual, and the specific frequencies produced by the acoustics may have helped to entrain the body and mind, helping the brain to produce an alpha wave brain pattern, and assisting in the achieving of an altered state of consciousness. It may be that the acoustic effects present were accidental artifacts of construction, but the acoustics of the space are so prominent, specific and well specified that it seems more likely that the acoustic consequences of the building of stone circular structures was understood at least to some extent. ${ }^{1}$

In conclusion, the research has shown that it is likely that Stonehenge was a venue for ritual musical activity in prehistory. It is still associated with ritualistic musical events that occur at the same place, on the same day of the year, for similar reasons and even with some similar attributes. Although we expect music and other cultural forms to change radically over time, Grauer (2006, pp. 15-7) suggests that "there is nothing 'natural' or intrinsic about cultural change, it does not just happen on its own, for no reason". From investigating the music of the past, and understanding something of the similarities and differences with sonic cultures today, we can learn more about the nature of music, and the nature of humanity.

It should come as no surprise that it is likely that Stonehenge featured music in prehistory, all ritual venues have music as a focus, whether cathedrals, churches or temples, and all music venues have associated rituals, whether theatres, clubs or opera houses. Popular music venues are the homes of cults of contemporary popular music, just as Parker Pearson et al. (2006) tell us that Stonehenge may have been the home of a prehistoric ancestor worship cult, and again it makes sense that the two cults have become associated. Musical tradition in prehistory would have developed at Stonehenge for the much the same reasons as it has developed there today, and some of the same agencies have been at work in both cases. A study of the acoustics and sonic culture of Stonehenge has been useful and enlightening, and reminds us how the study of music and its associated culture is able to provide a unique insight into human culture more generally. 


\section{Note}

1. This study of the acoustics and sounds of Stonehenge is ongoing, and further information can be found at http://soundsofStonehenge.wordpress.com. Information on a wider exploration of the acoustics and music of prehistory, can be found at http://AMBPnetwork.wordpress.com.

\section{Acknowledgements}

Dr. Bruno Fazenda created the mathematical model of Stonehenge and took part in field trips to Maryhill and Stonehenge to carry out acoustic field measurements, and continues to be an important part of this research project. The History Channel supported this research by arranging and filming visits to Maryhill and Stonehenge for their Mystery Quest series. All of the crew were very supportive, and I would like to thank in particular to Haewon Yom. Prof. Jian Kang, Director of Research in the University of Sheffield School of Architecture supported the research by allowing us use of a dodecahedron loudspeaker. 3D design company Imigea kindly allowed us use of their digital model of Stonehenge for the project. Prof. Mike Parker Pearson and Dr. Ben Chan of the University of Sheffield Department of Archaeology and the Stonehenge Riverside Project, have provided invaluable archaeological advice and assistance. The Thomas Hardy Association were most helpful in finding references to Stonehenge in the work of Hardy. Dr. Aaron Watson has supported this work through various discussions. Prof. Chris Scarre of the Department of Archaeology at Durham University provided valuable insights. Dr. Simon Wyatt provided input on the subject of prehistoric instruments. Thanks go to all those who have supported this project.

\section{References}

Akutek: The WWW Center for Search, Research and Free Sharing in Acoustics. 2009. 'Concert Hall Acoustics: Parameters', 1 April. <http://www.akutek.info/concert hall acoustics.htm>

Cleal, Rosamund. M. J., Walker, K. E. and Montague, R. 1995. Stonehenge in its landscape: Twentieth century excavations, English Heritage Archaeological Report 10, Swindon.

Daily Telegraph Website. 2009. 'Stonehenge Was Giant Concert Venue" 4 Jan. $<$ http://www.telegraph.co.uk/science/science-news/4108867/Stonehenge-was-giantconcert-venue.html>

Devereux. Paul. 2001. Stone Age Soundtracks: The acoustic archaeology of ancient sites, Vega, London.

Devereux, Paul. 2009. 'The Landscape and Perception Project', 21 December. <http://www.landscape-perception.com/>

Di Paolo, Ezequiel. A. 1999. On the Evolutionary and Behavioral Dynamics of Social Coordination: Models and Theoretical Aspects. DPhil Thesis, University of Sussex. <http://www.informatics.sussex.ac.uk/users/ezequiel/thesis/ch9>

Egner, Tobias., and Gruzelier, John. H. 2003. 'Ecological validity of neurofeedback: modulation of slow wave EEG enhances musical performance'. Cognitive Neuroscience and Neuropsychology, Vol. 14, No. 9, pp. 1221-1224.

Ehrenreich, Barbara. 2006. Dancing in the Streets: A History of Collective Joy, Metropolitan, New York. 
Entrainment Network. 2009. 'Experience and Meaning in Music Performance', 5 September. <http://www.open.ac.uk/Arts/experience/index.html>

Freeman, Walter. 2000. 'A Neurobiological Role of Music in Social Bonding' in N. L. Wallin, B. Merker, S. Brown eds. The Origins of Music, MIT Press, Cambridge, Mass.

Gibson, James. J. 1966. The Senses Considered as Perceptual Systems, Greenwood, London.

Grauer, Victor. A. 2006. 'Echoes of Our Forgotten Ancestors'. The World of Music, Vol. 48, no. 2, pp. 93-100.

Gray, John. 1991. African Music, Greenwood, London.

Hardy, Thomas. 1891. Tess of the D'Urbervilles, Macmillan, London.

Hawkwind - The Solstice at Stonehenge. 2004. Director: Hawkwind, Cherry Red.

Help!. 1965. Director: Richard Lester, United Artists.

History. 2009. Stonehenge, 'Mysteryquest Series 1' (episode nine), History Channel.

Imigea. 2009. 'Stonehenge 3D Virtual Reality', 21 September.

http://www.3dancientwonders.com/3d stonehenge virtualreality.htm>

Ingold, Timothy. 2000. 'Stop, Look and Listen! Vision, Hearing and Human

Movement' in Perception of the Environment: Essays on Livelihood, Dwelling and

Skill, Routledge, London, pp. 61-76.

Lorenzi, R., MSNBC. 2009. 'Stonehenge:One totally awesome rave location', 7 Jan. <http://www.msnbc.msn.com/id/28540927/>

Maryhill Museum of Art. 2009. 'Stonehenge Memorial', July 4.

<http://www.maryhillmuseum.org/do.html\#stonehenge>

McLuhan, Marshall. 1962. The Gutenberg Galaxy: The Making of Typograhic Man, University of Toronto Press, Toronto.

Mclver, Joel. 2006. Sabbath Bloody Sabbath, Omnibus, London.

Nettl, Bruno. 2000. 'An Ethnomusicologist Contemplates Musical Universals' in N. L. Wallin, B. Merker, S. Brown eds. The Origins of Music, MIT Press, Cambridge, Mass, pp. 463-472.

Odeon. 2009. 'Odeon room acoustics software', 5 November.

<http://www.odeon.dk/>

Orel, Harold. 1966. Thomas Hardy's Personal Writings: Prefaces, Literary Opinions, Reminiscences, University of Kansas Press, Lawrence.

Parker Pearson, Mike et al. 2006. 'Materializing Stonehenge: The Stonehenge Riverside Project and New Discoveries'. Journal of Material Culture. No. 11, pp. 22761.

Richards, Julian. 2007. Stonehenge: The Story So Far, English Heritage, Swindon.

St. John, Graham, ed. 2004. Rave Culture and Religion, Routledge, Abingdon.

Skålevik, Magne. 2009. 'Room Acoustic Parameters and their Distribution over Concert Hall Seats', 1 April.

<http://www.akutek.info/Papers/MS Parameters Distribution.pdf>

This is Spinal Tap. 1984. Director: Rob Reiner, Spinal Tap Productions/Embassy.

Till, Rupert. 2009. 'Possession trance ritual in electronic dance music culture: a popular ritual technology for reenchantment, addressing the crisis of the homeless 
self, and reinserting the individual into the community' in C. Deacy (ed.) Exploring Religion and the Sacred in a Media Age, Ashgate, London, pp.169-188.

Till, Rupert. 2009b. 'Acoustics and Music of British Prehistory Research Network', 4 August. <http://AMBPnetwork.wordpress.com>

Till, Rupert. 2009c. 'Sounds of Stonehenge', 21 December.

$<$ http://Soundsofstonehenge.wordpress.com>

Turow, Gabe. 2005. Auditory Driving as a Ritual Technology: A Review and Analysis.

Religious Studies Honours Thesis, Stanford University,

<http://www.stanford.edu/group/brainwaves/2006/AuditoryDrivingRitualTech.pdf >

Watson, Aaron. and Keating, David. 1999. 'Architecture and Sound: an acoustic analysis of megalithic monuments in prehistoric Britain'. Antiquity, No. 73, pp. 325336.

Whelan, A., The Sun Website. 'Henge a venue for partying says prof', 5 Jan. <http://www.thesun.co.uk/sol/homepage/news/article2094889.ece>

Wilson, Hugh. 2008. 'The healing stones - a new theory for an ancient icon', 18 August. <http://www.bbc.co.uk/history/programmes/stonehenge/article1.shtml>

Worthington, Andy. 2005. The Battle of the Beanfield, Enabler Publications, Eyemouth.

Wyatt, Simon. 2008. 'The classification of the clay drums of the southern trichterbecher culture (TRB)', 17 July. <http://www.jungsteinsite.unikiel.de/2008 wyatt/2008 Wyatt high.pdf>

\section{Discography}

Aerosmith. 1982. Rock in a Hard Place, Columbia, August, USA.

Black Sabbath. 1983. Born Again, Vertigo, September, UK.

Hawkwind. 1976. Astounding Sounds, Amazing Music, Atomhenge, August, UK.

Hawkwind. 1983. Zones, Flicknife, October, UK.

Richie Havens. 1970. Stonehenge, Stormy Forest, USA.

Ten Years After. 1969. Stonedhenge, Deram, UK. 